\title{
DOCUMENTO
}

\section{UM PROJETO DE EDUCAÇÃO COMUM NO BRASIL DO SÉCULO 19}

\author{
A common educational project in Brazil in the $19^{\text {th }}$ century
}

\author{
Eduardo Arriada \\ Universidade Federal de Pelotas, Brasil. \\ Elomar Antonio Callegaro Tambara \\ Universidade Federal de Pelotas, Brasil.
}

$\cos 80$

querela. A padronização de métodos e de estruturas curriculares uniformemente empregados tem merecido atenção dos estudiosos, tanto apregoando sua pertinência, quanto a entendendo como um malefício no processo de formação do estudante. A idéia de um currículo nacional, particularmente aquele direcionado à educação escolar fundamental, tem sido historicamente acalentada por muitos educadores e políticos no Brasil e, a rigor, está associada ao direito à cidadania.

Neste trabalho, apresentamos uma proposta elaborada no início do século 19 pelo padre Diogo Feijó, que possuía o ineditismo de apresentar um projeto de educação comum para todo o Brasil em plena vigência do Ato Adicional de 1834. É notável a desatenção dos investigadores da área da historiografia brasileira em geral e, da História da Educação em particular, para com este projeto que, como veremos, foi representativo 
de uma potente corrente de pensamento pedagógico do início do século 19, apesar de não hegemônica.

É abundante a produção científica em relação à vida pessoal e profissional de Diogo Feijó. Dentre muitos, destacam-se os trabalhos de Ellis Junior (1980); Ricci (2001); Orico (1930); Sousa (1942); Fleury (1958). Quanto à área da história da educação há trabalhos importantes que tratam deste período, como por exemplo: Saviani (2007); Almeida (1989); Barroso (2005); Haidar (1972); Mattos (1958); Moacyr (1936); Carvalho (1978); Gondra e Schueler (2008). Mesmo com o incontestável aporte destes trabalhos, observamos a lacuna quanto a esta particular contribuição do senador Feijó que, de per se, entendemos contribui para elucidar aspectos significativos do debate pedagógico do início da consolidação do sistema educacional brasileiro nos primórdios do período imperial.

Os procedimentos de configuração do sistema educacional brasileiro, de modo geral, têm merecido dos estudiosos a imputação de um ponto de inflexão - o Ato Adicional de 1834. Mesmo assim, é preciso ter presente que muitos dos autores que tem se debruçado sobre este período, entre outros Sucupira (1996); Saviani (2007); Cury, Castanha (2006); Costa (1999); Cunha (1980); Azevedo (1934), não são concordes sobre a interpretação dos efetivos resultados desta legislação. Há divergência, sobretudo, em relação à intensidade do processo de centralização ou descentralização decorrente das políticas administrativas deste período do Império.

De qualquer forma, somos partidários de que a primeira lei que legislou particularmente sobre ensino no período imperial, a lei de 15 de outubro de 1827, sofreu uma derrocada em seus princípios fundamentais. Não obstante que, já por ocasião da elaboração da Constituição de 1824, esta fosse uma questão posta, isto é, indagava-se sobre o papel e função dos diversos entes neste processo, particularmente os das províncias e da União Federal. ${ }^{1}$ Embora o Ato Adicional diga respeito à constituição de 1824, é sobre a lei, propriamente dita, que há uma interferência direta em termos de sistema de ensino. Aspectos fundamentais da mesma são apropriados de modo a propiciar interpretações convenientes para os diversos entes da União.

Talvez esta seja a questão crucial da recepção deste Ato pela sociedade civil e, particularmente, pela política e, em conseqüência, pelos diversos organismos executivos da estrutura administrativa imperial brasileira.

Para certas atribuições houve rechaço ou acolhimento que atenderam a interesses bem delineados pelos desejos ou necessidades de segmentos de poder. Esta situação gerou, entre outras demandas, a controversa polêmica que desembocou na Lei da Interpretação de 1840.

Note-se que, desde sua promulgação, aspectos importantes regidos pelo Ato Adicional foram questionados e, de certa forma, interpretados de modo distinto pelos diversos segmentos da sociedade.

No caso específico da área da educação, um exemplo que a seguir analisaremos com maior acuidade, é o projeto de lei sobre educação que Diogo Feijó, como senador do

\footnotetext{
${ }^{1}$ Como aponta Cury (1996), as perguntas clássicas sobre os justos limites dos entes juridicamente autônomos no jogo União versus unidades federadas se expressam também no âmbito de currículos mínimos para todos os cidadãos em qualquer Estado ou município. Assim, pode-se interrogar: invade-se o território da autonomia dos estados quando a União impõe uma lista mínima de disciplinas? E o que dizer quando ela avança no sentido de um detalhamento destas?
}

\begin{tabular}{|l|l|l} 
Hist. Educ. [Online] & Porto Alegre & v. 18
\end{tabular}

ก. 44

Set./dez. 2014

p. $203-220$ 
Império, apresentou com abrangência para toda a União, em 1839, portanto, em plena vigência do Ato Adicional.

Embora o projeto não tivesse chegado ao final de seu trâmite regimental, a discussão, para surpresa do autor, foi intensa e acalorada no plenário do Senado. Mas é importante perceber que apenas uma vez a questão de conflito com o Ato Adicional em si foi suscitada em plenário. Esta ocorreu em um aparte do senador A. Albuquerque quando, tratando de outro assunto relacionado com o projeto de lei de interpretação do Ato Adicional, se pronunciou em relação ao projeto de Feijó:

Não sei eu seja possível fazer um sistema de instrução que aproveite a toda a mocidade [...]. Eu não sei qual seja este sistema universal que se inculca, quando as Assembléias Provinciais tem direito de tratar dos sistemas de instrução; por isso, não sei como aqui se há de fazer um plano de instrução universal. (Sessão de 31 de maio de 1839, p. 276)

Que elementos estariam envolvidos no sistema produtivo então em constituição que, não obstante recepcionasse muitas das características do período colonial, como a produção sistematizada por esteios econômicos alicerçados no latifúndio e na escravidão, sem dúvida, também recepcionava, pelo menos em nível de representação parlamentar, e, eventualmente ideológica, concepções decorrentes de tendências progressistas vinculadas ao pensamento liberal?

Estes elementos, por vezes antagônicos e quiçá contraditórios, consubstanciavamse, por exemplo, na atuação dos exaltados no Congresso Nacional ou que no mesmo Congresso se referendassem posicionamentos galico-regalistas da maioria do clero parlamentar, tão numeroso nas diversas legislaturas deste período, conquanto seja importante ressaltar quão liberais muitos grupos se apresentassem na defesa de preceitos avançados em áreas sociais, como os vinculados à instrução e à religião e, concomitantemente, se revestissem de vestes conservadoras em termos econômicos, como a defesa da manutenção da escravidão, por exemplo. Particularmente na área do ensino, sobrevivências arcaicas se enfrentavam com pretensões reformistas.

Mesmo assim, não resta dúvida de que muitos projetos político-sociais estavam em disputa e que houve um processo de acomodação social, ao final com a vitória de segmentos vinculados ao conservadorismo social e representativo de práticas sociais e econômicas que engessaram o Brasil por longo período em termos de desenvolvimento das forças produtivas. Ressaltamos, neste particular, justamente a predominância de uma estrutura agrária latifundiária e de um sistema produtivo escravocrata, naquele momento, já anacrônicos sob a lógica produtiva de um sistema capitalista de produção.

O trâmite parlamentar deste projeto ocorreu concomitante ao das discussões sobre a interpretação do Ato Adicional, revelando, de certa forma, a perspectiva de Feijó sobre a abrangência do mesmo em termos de atribuição da manutenção da educação pela União e ou pelas províncias.

Como é sabido, a lei de 15 de outubro de 1827 mandara criar escolas de primeiras letras em todas as cidades, vilas e povoações do Império. E esta era uma atribuição do 
governo central. Entretanto o Ato Adicional determinava, em seu artigo $10^{\circ}$, que tal tarefa competia à instância provincial ${ }^{2}$ :

Compete às mesmas assembléias legislar: [...] II. Sobre a instrucção pública e estabelecimentos próprios a promovê-la, não comprehendendo as faculdades de medicina, os cursos jurídicos, academias actualmente existentes, e outros quaesquer estabelecimentos de instrucção que para o futuro forem creados por lei geral. (Brasil, 1863, p. 171)

Apesar desta cláusula aposta ao final do artigo que, teoricamente, permitia uma interpretação a qual autorizaria a atuação do governo Imperial, a mesma nunca foi lembrada para justificar a ação do governo central na área do ensino primário, reservando-se o mesmo como mantenedor do ensino no município da corte e do de nível superior no território nacional, de modo que, por um século - até a Constituição de 1934 o governo central, legalmente, enfrentou obstáculos em atuar na área do ensino primário ${ }^{3}$.

O caráter de pioneirismo de Feijó é evidenciado não somente pela tentativa de implantar uma educação comum em todo o território nacional, o que não é pouco, mas também, e talvez principalmente, pela natureza da base curricular que privilegiava aspectos bastante controversos. Destaca a implantação de um efetivo processo de laicização do ensino, pois em todo o projeto não há referência alguma ao ensino religioso que é substituído, de forma justificada, pela Filosofia Moral. Ademais, também chama a atenção, entre outros aspectos, por ser proposto em plena vigência do sistema de padroado e ainda por ser sugerido por um clérigo.

Neste sentido, o senador antecipou-se às concepções positivistas ao privilegiar os estudos das ciências físico-naturais em detrimento dos estudos humanísticos. Não custa lembrar que o Brasil ainda rescaldava-se das medidas pombalinas de implantação desastrosa do ensino régio com a expulsão dos jesuítas.

As diversas concepções ideológicas sobre sistema de ensino e grade curricular puderam então ser percebidas na discussão que se estabeleceu entre o autor, senador padre Diogo Feijó, e o senador Bernardo Pereira de Vasconcelos, que fez uma detalhada apreciação do projeto, apontando-Ihe várias ressalvas. É importante lembrar, também, que neste momento o senador Bernardo Pereira de Vasconcelos já havia feito sua migração do radicalismo do Partido Liberal para o Partido do Regresso. Apesar de reconhecer a necessidade de um sistema nacional de ensino, ele apontou vários

\footnotetext{
2 Segundo Cury (1996), "até 1834, o Império tem a responsabilidade de manter tais escolas como oferta gratuita aos que viessem procurá-las. O Ato Adicional de 1834 introduz não só a divisão de competências entre "os poderes gerais" e as províncias, como também deixa na ambigüidade se tal responsabilidade deveria ser compartilhada ou privativa das províncias. Essa ambigüidade sempre acabou permeando as discussões sobre a dinâmica centralização versus descentralização, mesmo antes de nossa República proclamada se dizer federativa."

3 Para Holanda, "em 1834, o Ato Adicional consumou o desastre para nosso sistema educacional, atribuindo competência as assembléias provinciais para legislar sobre o ensino elementar e médio. [...] Longe de incentivar progressos locais, que poderiam ter sido mais facilmente atingíveis sem um excessivo centralismo, serviu somente para fortalecer o jogo de interesses de grandes latifundiários que agiam, a seu bel-prazer, em territórios mais ou menos extenso. Se a elite do país, reunida no legislativo e na administração do Governo geral, pouco fez em prol do ensino primário, que se poderia esperar das províncias, onde o domínio autocrático dos latifundiários se fazia sentir profundamente, sendo que eles não tinham o menor interesse pela educação do povo?" (1985, p. 377)

\begin{tabular}{|l|l|l|l|l|l|}
\hline Hist. Educ. [Online] & Porto Alegre & v. 18 & n. 44 & Set./dez. 2014 & p. 203-220
\end{tabular}
}


problemas da proposta do senador Feijó, particularmente relacionados ao ensino religioso e a base de instrução fundamentada nas Ciências Físicas e Naturais.

Nota-se que a preocupação de Feijó estava relacionada diretamente com um projeto de integração nacional, objeto, aliás, muito associado a sua atuação como regente. Não há dúvida que os diversos movimentos segregacionistas que apareceram em muitas províncias e que foram reprimidos, todos eles, com força militar de forma contundente, levaram-no a dimensionar a necessidade do estabelecimento de um aparelho ideológico com capacidade de instituir um laço efetivo e eficaz de união e coesão nacional. Neste sentido, se manifesta:

Há muito tempo que estou convencido de que a educação é necessária, não só para o individuo como para uma nação e que assim é a primeira necessidade do Brasil um plano geral de educação, se em verdade desejamos dar aos brasileiros um caráter nacional. (Sessão de 31 de maio 1839, p. 263)

Diogo Feijó atribui à educação pública uniforme a propriedade de constituir um processo civilizatório mais consentâneo com o projeto desenvolvimentista em consolidação e que poderia, afastando-se de procedimentos individualistas e particularistas, coadunar-se com os ideais de construção de uma nação com padrão uniforme e uno, distanciando-se do que ocorreu, por exemplo, na América espanhola:

Indispensável o estabelecimento de uma educação pública uniforme em todo o Brasil; e se nós bem observarmos o espírito de nossa nação, teremos de confessar que no Brasil cada individuo tem um caráter particular, quando, no mesmo antigo Governo absoluto, podia reconhecerse em todos os brasileiros um caráter distintivo, porque havia uma educação, ainda que algum tanto uniforme e essa educação era geral. Em toda a parte se encontravam os mesmos estudos, os mesmos princípios regulavam o pensamento de todos, o que não acontece hoje; a educação de hoje consiste em aprender a ler. Ora, bem se sabe que ler e escrever é indispensável, porque é o instrumento do saber; para se saber alguma coisa mais, cumpre que se aprendam idéias novas, que se procure primeiro desenvolver a razão, para esta habilitar-se a compreender verdades que lhe sirvam no resto da vida. (Sessão de 31 de maio 1839, p. 264)

O método proposto por Feijó tinha a intenção de subverter toda a lógica do sistema de ensino vigente, que estava ainda eivado de influência da Ratio Studiorum, apesar do todo o esforço de superação desta prática pedagógica efetuado pela Instrução Régia de cunho regalista. Um primeiro aspecto marcante da proposição é a eliminação do Latim e das humanidades como os princípios norteadores do ensino.

Segundo Feijó, "o nosso antigo método de principiar o estudo pela gramática latina eu chamarei infernal (sic): semelhante estudo é árido, enfadonho, ininteligível e sem aumentar o número de nossas idéias, só serve para tornar odiosos os mais estudos" (Sessão de 31 de maio 1839, p. 264).

Nota-se, no senador, uma verdadeira ojeriza à Gramática Latina, o que ensejou, nas discussões em plenário, interpretações e questionamentos de toda ordem. Em princípio, a idéia do projeto é restringi-la, fundamentalmente, aos postulantes à carreira eclesiástica. Esta luta inglória, até o final do Império, foi defendida por muitos intelectuais sem 
sucesso. Por exemplo, Tavares Bastos (1862), em Cartas do solitário, afirmava: "livrai-o [o aluno] dos mestres pedantes de latim e retórica, e o jovem será um cidadão útil à pátria, um empresário, um maquinista."

Há, no projeto, uma ênfase aos conteúdos técnicos ou pelo menos em matérias mais relacionadas com tópicos vinculados às consideradas ciências exatas. De certa forma, há uma clara assunção de princípios iluministas mais conectados aos conhecimentos científicos vinculados às ciências naturais, à matemática, à física, à química.

Não devemos olvidar que não era uma experiência de todo original no Brasil. Um exemplo conhecido de implantação de um sistema de ensino com esta perspectiva foi a fundação do Seminário de Olinda, em 1800, sob a supervisão do bispo D. José Joaquim da Cunha de Azeredo Coutinho, que introduziu, com maior ênfase, dentre outras disciplinas, o ensino da Botânica e da Mineralogia, do Desenho, da Química, das Ciências Físicas e Matemáticas.

O que se nota é que o trabalho da Companhia de Jesus representou um relativo sucesso no que se propôs como comando avançado da Igreja Católica a ponto de, no momento de sua expulsão, ter já executado seu principal objetivo: o Brasil estava todo ele sob uma mesma fé e sob um mesmo comando, de maneira que os movimentos que tentaram romper com as estruturas ideológico-culturais construídas sob a supervisão jesuítica encontraram inúmeras dificuldades.

As teorias enciclopedistas, cujo Seminário de Olinda é um resultado, não tiveram a capacidade nem a força para romper com a unidade cultural e, particularmente, em interferir no sistema de ensino como um todo. A agitação revolucionária do início do século 19 foi fatal à instituição. Assim, mesmo tendo tido uma contribuição decisiva na formação de um clero liberal, que se consubstanciou, por exemplo, nos movimentos sediciosos do início do século 19, notadamente a Conspiração de 1801 e a Revolução 1817, período em que mais de 50 sacerdotes sofreram as conseqüências da repressão imperial, tal mentalidade contribuiu, decisivamente, para o enfraquecimento da lgreja Católica perante o governo brasileiro.

Outro exemplo, bastante conhecido, é a atuação dos padres lazaristas que, na verga do modelo jesuítico fundaram, em 1820, o Colégio Caraça de Minas Gerais, que se constituiu num dos maiores estabelecimentos de ensino secundário do Império. No período de 1820 a 1835 sua matrícula atingiu a mais de 1.500 alunos. $^{4}$

Esta resistência atingiu, também, a principal congregação religiosa católica que no âmbito da Igreja antagonizou com a Companhia de Jesus, os oratorianos ${ }^{5}$, que tiveram

\footnotetext{
${ }^{4}$ Evidentemente que ao espírito anticlerical não ficava obliterado nesta vinculação. Assim, por exemplo, o jornal Aurora Fluminense, que havia assumido posição nitidamente anticlerical, em 18 de fevereiro de 1828, escrevia: "Todo o mundo se ocupa atualmente com a famosa Sociedade de Jesus; o seu espírito, as suas máximas, o seus planos e sagaz hipocrisia, dão objeto a muito discursos e reflexões, agora que aquela hidra parece querer levantar na Europa as decepadas cabeças. Também nos entretemos um pouco com Jesuítas; mas com Jesuítas de nova espécie, que marchando pelas pisadas dos primeiros, são mais para recear, porque não acham contra si nenhuma prevenção desfavorável: falamos dos padres da Congregação da Missão, estabelecidos na Serra do Caraça em Minas Gerais" (apud. Martins, 1977, p 170).

${ }^{5}$ Esta rivalidade entre estas congregações religiosas se consubstanciou na conhecida compe-tição entre as gramáticas latinas: a do padre Antonio Pereira de Figueiredo, de preferência dos oratorianos, e a do padre Manuel Álvares, utilizada pelos jesuítas, retratava dois projetos pedagógicos bastante diversos.
} 
grande dificuldade em se estabelecer no Brasil e que após vários problemas e escândalos de toda ordem tiveram seu estabelecimento fechado. ${ }^{6}$

Deve-se ter em mente que havia o germe de um verdadeiro complô contra as ordens religiosas no Brasil e que no parlamento tinha como porta-vozes elementos do próprio clero. Em 1830, o padre Venâncio Henriques de Resende deixava muito claro sua posição:

Todos sabem que no Brasil os frades são desnecessários; contudo não queria desde já dar um golpe nessas ordens religiosas que temos, porque são estabelecidas legalmente: mas estes que vem para o nosso território mendigar, não os posso sofrer, queria que pagassem um conto de réis por cada um na alfândega. (Sessão de 26 de Junho de 1830, p. 59)

Esta manifestação está circunscrita à discussão de um projeto de lei do próprio padre que rezava em seu artigo $1^{\circ}$ : "Fica proibido o estabelecimento de novas casas religiosas, de qualquer título ou denominação que sejam". A luta contra os religiosos apenas começava ${ }^{7}$ e só terminaria na República. Ademais, fica evidente que o clero secular, como o governo, viu com ressalvas o ingresso de religiosos no Brasil por todo o período imperial. $^{8}$

Consoante, é importante ter presente que a Questão Religiosa não foi simplesmente um ataque de governos maçônicos contra os princípios doutrinários católicos. Posições regalistas e galicanas foram assumidas, no Brasil, desde a época da independência, por renomados sacerdotes e até por membros da mais alta hierarquia eclesiástica. $^{9}$

Entretanto, por todo o século 19 a Igreja ultramontana fortificou-se, numa clara guerra de posições que, se por um lado, agudizou o conflito, por outro, possibilitou um

\footnotetext{
${ }^{6}$ Houve medidas diretas de extinção decretadas contra vários institutos religiosos no período imperial: Congregações de São Filipe Néri, Carmelitas, Capuchinhos de Pernambuco e outras mais (leis de 1830, 1831, 1835 e 1840), assim como as instruções de 1824, do ministro Vidigal, que determinavam o rompimento das casas religiosas do Brasil com as casas provinciais na Europa, e o decreto de 1855, de Nabuco de Araújo, que proibia o noviciado das ordens religiosas.

${ }^{7}$ É difícil caracterizar o efetivo início deste processo, pois já na discussão da Constituinte pode-se observar ações com este intuito. Em 24 de maio de 1823 o deputado José Antonio Caldas apresentava o seguinte projeto: " $1{ }^{\circ}$ Fica proibido provisoriamente da data do presente decreto em diante, até que a assembléia delibere o contrário, a admissão de qualquer pessoa à entrada para noviciado em todos os conventos de um e outro sexo, podendo somente ser admitidos à profissão os que estando já no noviciado quiserem professar. $2^{\circ}$ Qualquer regular do sexo masculino, que quiser poderá sair do convento, precedendo licença pontifícia, que será requerida, e protegida pelo governo; ficando os egressos hábeis para ocupar os ofícios civis ou eclesiásticos, como outro qualquer cidadão."

${ }^{8}$ Note que esta era uma questão recalcitrante. Cinco anos mais tarde, o mesmo sacerdote apresentou um projeto com o seguinte teor: "1) Fica proibido na Corte e município do Rio de Janeiro o ingresso e profissão religiosa nos conventos de padres e freiras de toda e qualquer denominação que sejam. 2) Em nenhum dos conventos se admitirão frades de fora, nem mesmo das respectivas ordens, para residência fixa, à exceção dos atualmente conventuais nas referidas casas. 3) Estas casas ficam desde já independentes de toda e qualquer autoridade dos capítulos e prelados gerais ou provinciais residentes fora do município, observando em tudo o mais, os estatutos da ordem" (Sessão de 4 de julho de 1835, p. 22).

9 llustrativo é o número de sacerdotes parlamentares que integravam a Assembléia Legislativa, de 1826 a 1829, e que não titubeavam em reconhecer o primado do poder do Estado sobre o Eclesiástico, entre eles Januário da Cunha Barbosa, Diogo Feijó, Miguel Reinaut, monsenhor Pizarro, Custódio Dias, José Bento Leite Ferreira de Mello, Rocha Franco.
} 
enfrentamento que garantiu o processo de romanização da mesma, particularmente no início do século 20. Segundo Martins,

nem tanto, de resto, e essas reações mostram, por sua simples ocorrência, que o clima estava mudando. Com efeito, a partir da Maioridade, nota-se uma sensível guinada em favor do ultramontanismo. Antes de mais nada porque os projetos em que estão interessadas as ordens religiosas já não despertam mais a oposição virulenta da Câmara. Em seguida, porque a linguagem muda por completo: desaparecem as alusões ferinas, as críticas, os comentários desagradáveis. Depois, aparecem pouco a pouco os projetos favoráveis à igreja: loterias para as ordens religiosas e reconstrução dos templos (como para o teatro!), auxílios, côngruas, etc. (1977, p. 254)

De resto, fica patente que a educação de cunho predominantemente humanístico ainda era hegemônica no início do século 19. O próprio colégio D. Pedro II, criado em 1837, se caracterizou por apresentar-se como um ícone do humanismo no Império:

o Colégio Pedro II, apesar de seu bom nível em relação ao que então aqui existia e não obstante terem saído de seus cursos muitos homens ilustres que iriam influir no país, não pode desempenhar o papel de um centro de ciência e pesquisa de que o Brasil tanto necessitava, em virtude de seu ensino, se prender, demasiadamente, ao estudo das letras e humanidades, com pequena concessão aos estudos científicos. (Holanda, 1985, p. 372)

A criação deste estabelecimento de ensino secundário é um retrato do processo de secularização do ensino ensejado no campo de disputa que ocorria no início do século 19 no Brasil. E, sob certo aspecto, apesar de poder ser considerado como o ápice do mesmo, revela seu limite, a ponto de, a partir da década de 1840, haver o início da recomposição ultramontana de suas hostes civis e eclesiásticas que desembocaram, na década de 1870, na Questão Religiosa e, posteriormente, no fim do Regime de Padroado, por ocasião da proclamação da República.

De qualquer forma, no período que estamos analisando fica nítida uma intensificação na tensão entre o poder da Igreja Católica, vinculada a Roma, e o governo imperial. A criação do Colégio de D. Pedro II, e de outros estabelecimentos de ensino seculares, apesar da natureza jesuítico-humanística de que estão revestidos, se constituem em um êmulo aos interesses do ultramontanismo em termos de organização pedagógica.

Como assinala Martins,

em 1832, o antigo Seminário de Olinda foi transformado em Colégio de Artes, funcionando como propedêutico ao curso jurídico, assim como, cinco anos mais tarde, outro seminário, o de $\mathrm{S}$. Joaquim, no Rio de Janeiro, seria secularizado e sucessivamente convertido em escola primária e profissional, e logo, em dezembro de 1837, em colégio secundário, com o nome de Pedro II. São alterações que testemunham por assim dizer materialmente o irresistível impulso para a secularização do ensino. (1977, p. 231)

Por conseguinte, foi sob este clima que combinava, de um lado, mecanismos de acomodação política e, de outro, uma expectativa de mudança em virtude do processo de 
consolidação de determinadas práticas capitalistas, que o ex-regente apresentou no Senado da União o projeto de educação comum para o Brasil em 31 de maio de 1839.

Desde logo, o projeto de Feijó defendia o método intuitivo com relação ao formato de tratar os conteúdos: "O essencial deste método é principiar pelos conhecimentos sensíveis, passar aos inteligíveis e concluir pelos morais" (sessão de 31 de maio de 1839 , p. 264).

Por fim, surpreendentemente para um clérigo, ele prescinde da instrução religiosa ministrada em sala de aula. Aspecto este que provocou críticas as mais contundentes dos adversários do projeto. Mas segundo Feijó,

depois de desenvolvida a razão do menino pelos elementos da ciência que indico, ele ultima a sua aplicação pelo estudo de filosofia moral, a fim de que fique cabalmente instruído nos seus direitos e deveres. Assim habilitado, pode o menino seguir a carreira que quiser ou para a qual as circunstâncias o chamarem. (sessão de 31 de maio de 1839, p. 264)

A contenda que se estabeleceu no plenário do Congresso Nacional reflete as relações sociais que se formaram no Brasil, no período imperial, fruto de um sistema econômico baseado na escravidão. Desta forma, a generalização de uma educação comum para todo o território nacional, com as características técnicas propostas por Feijó, em contraposição à educação humanística em voga, não podia deixar de receber críticas de setores interessados na manutenção do status quo.

Como bem aponta Holanda,

o desprezo completo que a elite do país nutria pelo trabalho, sobretudo pelo trabalho manual, o que estava bem de acordo com a estrutura social e econômica vigente - explica, em parte, o abandono do ensino primário e o total desinteresse pelo ensino profissional. A repulsa pelas atividades manuais levava essa elite a considerar vis as profissões ligadas às artes e aos ofícios. (1985, p. 369)

Em seu Plano de estudos elementares Feijó apresenta, com objetividade, a seqüência dos conteúdos que entendia melhor se adequar ao processo de aprendizagem. Em primeiro lugar a História Natural. Em segundo a Física, seguida da Química. Em quarto a Geografia. Depois desta formação básica, o aluno complementaria a formação com a Metafísica e a Filosofia Moral. Este é o conteúdo que todo aluno deveria ter como base comum em todo o Império.

Inicia-se com a História Natural,

caminhando-se a par da natureza, observa-se que na aquisição dos conhecimentos tem o primeiro lugar os sensíveis; os quais ao passo que aceleram o desenvolvimento da sensibilidade, subministram os primeiros materiais dos conhecimentos humanos. Ocupa o primeiro lugar neste plano a História Natural, a qual apresentando em classes os diferentes objetos que rodeiam o homem e que com ele tem relação, consegue que seus sentidos sejam saciados, sua curiosidade satisfeita, sua memória desembaraçada, a sua razão principie a empregar sem obstáculos os primeiros esforços de sua atividade. (Sessão de 31 de Maio de 1839, p. 265) 
Posteriormente, o aluno conheceria os conteúdos de Física e Química. Nota-se a preocupação em impregnar o aprendizado do aluno com conhecimentos vinculados aos aspectos concretos da vida, como justificado por Feijó em seu plano de estudos:

Ocupa o segundo lugar a Física, que por meio de uma classificação mais apurada, aproxima objetos que pareciam diferentes e que pela natureza fará conhecer propriedades incógnitas e que mereciam uma cega admiração. Ocupa o terceiro lugar a Química, que pela decomposição da matéria descobrirá os seus principais elementos, pondo o homem ao alcance de muitos segredos da natureza, da força de seus principais agentes e da sua feliz aplicação às artes. (Sessão de 31 de maio de 1839, p. 265)

A seguir, paulatinamente o aluno se apropriaria dos conhecimentos mais abstratos, particularmente os vinculados ao domínio da Geografia, também compreendidos os conhecimentos históricos, sociais, políticos:

Quando o domínio dos sentidos parece enriquecer pelos estudos precedentes, convém saltar a limitada esfera da própria observação e aprender pela autoridade, com o socorro da imaginação e dos mesmos sentidos, novas verdades que dever servir de suplemento à própria experiência. A Geografia, portanto, na qual se dê somente a idéia geral do globo e de suas diferentes partes; a divisão dos principais estados e do que há de mais raro e admirável em cada um deles; em breve noticia de origem dos povos, das religiões e governos, fará que o homem conhecendo o mundo que habita rompa o estreito círculo de suas idéias, adquira uma certa expansão d'alma, que o torne concidadão de todos os habitantes da Terra. (Sessão de 31 de maio de 1839, p. 265)

Em termos de conhecimentos técnicos estaria o menino instruído e, então, apto a constituir-se como cidadão e capaz de integrar-se na nova sociedade podendo, inclusive, desempenhar funções nos quadros administrativos e políticos da sociedade brasileira com sucesso. Mesmo assim, havia a necessidade de uma lapidação deste aprendizado, que aconteceria pela Metafísica e, particularmente, da Filosofia Moral. Feijó preocupa-se, por demais, em justificar estes elementos de seu plano de estudos. Em verdade, ele já previa os ataques que viriam de setores vinculados à Igreja Católica que prescreviam o ensino religioso para o exercício desta função.

Neste sentido, esmera-se o senador em sua justificativa:

Instruído o homem até aqui do que se passa fora dele, convém tornar suas vistas sobre si mesmo; e a primeira e principal questão que o deve ocupar é a origem de seus conhecimentos. A observação sobre a alma; o desenvolvimento de suas faculdades; a manifestação de suas leis; os sentidos e a reflexão: enfim, as verdades primitivas, que servem de base a todos os conhecimentos humanos, analisadas, classificadas e notadas com o seu valor respectivo, Ihe oferecerão dados suficientes para resolver tão importante questão. A ciência das ciências ou a ciência dos princípios, isto é, a Metafísica, fará o homem certo do que é real e fenomenal; do que é objetivo e subjetivo e colocando-o no mais alto das abstrações, Ihe entregará a chave dos conhecimentos humanos; e se for ajudado do gênio poderá fazer progressos no desenvolvimento e aplicação destes princípio a toda outra ciência particular. Esta é a ocasião em que o homem já exercitado em refletir deve indagar as regras fixas e invariáveis que o 
conduziram e que o devem conduzir na investigação da verdade. A análise do pensamento the oferecerá os mais felizes resultados. Uma lógica, portanto, que apresente o quadro das operações do entendimento para o fim de raciocinar; as diferentes formas do raciocínio: os diferentes métodos de observar, de classificar, de meditar, de conjecturar, enfim, de rever seus conhecimentos pela aplicação da crítica, dos sinais, dos sentidos, da autoridade e da razão e algumas regras de disputar, desempenhará sem dúvida os fins da grande arte de pensar. Parece que com estes estudos elementares se achará desenvolvida a capacidade humana e subministradas as primeiras matérias dos seus conhecimentos e habilitado, portanto, o homem para aplicar-se ao estudo que melhor the convier. Sem dúvida nenhum outro é de tão absoluta necessidade como a filosofia moral; a qual, dando a conhecer a natureza moral do homem, fará nele rever o sentimento da sua dignidade, pela nobreza dos motivos que devem dirigir ações e pelo fim elevado, a que o destinou o autor da natureza. O sentimento inato da justiça o conduzirá a crer na necessidade de um Juiz Supremo, reto e imparcial; bem como de uma vida futura, onde postas em harmonia suas inclinações, tenha a virtude a necessária recompensa. Neste estudo aprenderá o homem em detalhes seus direitos e seus deveres e na teoria da felicidade saberá distinguir a falsa da verdadeira. Pela aplicação da legislação natural ao estado social, conhecerá os vícios e a perfeição das diferentes constituições; portanto o direito político se encarregará de mostrar a origem das sociedades legítimas: o seu verdadeiro fim; os meios de promover sua prosperidade, as diferentes formas de governos, suas vantagens e inconvenientes, enfim, as garantias necessárias para preservar a sociedade do flagelo da anarquia ou despotismo. Com este curso parece completar-se a educação comum de todo cidadão. (Sessão de 31 de maio de 1839, p. 265)

A crítica mais forte ao projeto proveio do senador Bernardo de Vasconcelos que, na sessão de 12 de junho, em longo discurso, tentou desconstruí-lo de forma enfática, apesar de ser também um defensor da tese da educação comum. Os argumentos são de toda a ordem. Um primeiro diz respeito à universalização destes conhecimentos. $O$ senador é a favor de uma educação comum, mas apenas para os primeiros estudos "na instrução primária simples, e não em conhecimentos mais subidos como os que trazia o projeto" (Sessão de 12 de Junho de 1839, p. 370).

Há, por inferência, uma interpretação de caráter pedagógico:

Não há coisa mais perigosa em a ciência da educação do que os princípios gerais, de que a pretensão de formar todos os homens pelo mesmo modelo [...] O projeto oferece a instrução nestas ciências a todos os cidadãos; nem os admite aos cargos públicos, ou eletivos ou mesmo da nomeação de qualquer autoridade, sem que eles tenham seguido um curso destes conhecimentos. (Sessão de 12 de junho de 1839, p. 370)

Este posicionamento é respondido na sessão seguinte pelo ex-regente:

Disse-se mais que a instrução muito generalizada é prejudicial aos mesmos cidadãos porque, tendo todos instrução, todos aspirariam aos empregos públicos e o número de aspirantes teria de sobrepujar ao dos lugares. Deste modo o nobre senador tem resolvido uma questão muito debatida, isto é, se convém mais a ignorância do que o saber. Eu, porém, decido a questão de outra maneira. Já eu disse que no sistema representativo o cidadão toma grande parte nos negócios públicos; ele, 
porem, não pode ser útil ao Estado nem a si mesmo, sem ter a sua razão desenvolvida. (Sessão de 14 de junho 1839, p. 386-7)

Vasconcelos entende que um dos problemas do projeto é o fato do mesmo centrar os estudos nos conhecimentos científicos em detrimento das Letras. Em vários momentos refere-se ao progresso de nações europeias, que teriam obtido seu desenvolvimento social e econômico alicerçado em uma educação de cunho humanístico ${ }^{10}$. Para ele, "não é pois, só defeituoso o projeto nas doutrinas que manda ensinar nessas escolas elementares; peca também em excluir as letras do ensino da mocidade, estabelecendo como base única da instrução o estudo das ciências" (Sessão de 12 de junho de 1839, p. 371).

Trava-se um demorado conflito de opiniões em que os defensores do projeto criticam de forma veemente o ensino de Letras, particularmente o Latim. Para ilustrar esta posição reproduziremos algumas das concepções emanadas em um aparte ao senador Bernardo Vasconcellos pelo senador Carneiro de Campos:

Como é que a um menino que principia a traduzir se manda logo a aprender não só Tito Livio, mas Horacio? O resultado disto era ser o menino massacrado com palmatoadas, e depois ficar acanhado do espírito, medroso e tímido, e adquirir um horror ao estudo das ciências e à aquisição dos conhecimentos. [...] De que serve o conhecimento das línguas sábias para um homem que houver de ser maquinista, serralheiro, e mesmo agricultor? E que coisa é mais necessária do que a aritmética? (Sessão de 12 de junho de 1839, p. 378)

E arremata: "e ainda hoje estou persuadido de que mais proveitoso será aos do Piauí saberem capar bezerros, fazer queijos, do que ter um cento de cadeiras de gramática latina" (Sessão de 12 de junho de 1839, p. 379).

Não deixa de ser interessante observar que Feijó, um sacerdote católico, um século antes de alastrar-se com maior força a defesa da escola neutra, venha a defendê-la de forma incisiva e, neste sentido, acompanhado por outros clérigos parlamentares. A rigor, quem amparou com maior vigor a necessidade do ensino religioso nas escolas foram parlamentares leigos comandados por uma liderança eclesiástica, o bispo D. Romualdo.

Já em 1830 Feijó se manifestara de forma inquestionável sobre este tema:

Não me parece muito conforme à Constituição que tem considerado os princípios da tolerância, o ensinar nas escolas dos dogmas da religião Católica Apostólica Romana. Essas escolas privam os pais que julgam que seus filhos ainda não estão no estado de escolher uma religião; e não estou bem lembrado se essa lei manda ensinar os princípios da moral cristã; por isso que são princípios de Direito Natural que convém a todos os estados e a todas as religiões; eis aqui por que eu digo que não se deve obrigar por força a que se aprenda uma religião que não querem. Ora, estes princípios de moral cristã que estão determinados pela lei é que se ensinam, e de certo o Governo podia fazer por isso em prática, porquanto o Governo, quando os mestres não satisfaçam a lei, tem autoridade para os suspender. (Sessão de 12 de maio de 1830, p. 121)

${ }^{10}$ Afirmava Vasconcelos: "Se consultasse a história, veríamos que todos os povos principiam a sua civilização pelo estudo das letras, com preferência às ciências; estas vêm depois, só vivem, só aparecem com o auxilio das letras; não há um fato histórico que desminta esta verdade." (Sessão de 12 de maio de 1830, p. 371). 
O grupo de padres parlamentares mais atuante no Congresso Nacional pauta seu desempenho pela defesa de que o ensino religioso deveria ser dado nas igrejas, pelos párocos. E se isto não ocorria era por incúria do governo que não fiscalizava o exercício dos párocos. Este é um ponto do projeto de Feijó que Bernardo de Vasconcelos contesta com veemência:

O nobre autor do projeto não trata do ensino da religião do Estado; eu reconheço quanto a moral influi no homem, quanto a moral universal influi na educação e marcha do homem; reconheço que ele foi gravado em nosso coração pela mão da Providencia; mas não me parece que ele seja suficiente; em uma ou outra vez basta para as nossas relações domésticas e mundanas, nem sempre ela ministra todos os preceitos e crenças que são necessárias a um país. (Sessão de 12 de Junho de 1839, p. 371)

Na sessão de 14 de junho de 1839, Feijó contrapõe este argumento:

Outra falta foi notada: a do estudo da religião; mas todos sabem que a religião se aprende na infância e que a Igreja é a verdadeira mestra dos dogmas e da moral religiosa, que os bispos e os párocos são obrigados a ensiná-la; e se estes ministros da Igreja não cumprem com este dever tão importante, a culpa é de quem está à testa dos negócios públicos, que deve adverti-lhes seus deveres, para cujo desempenho o Estado faz grandes despesas com os ministros do culto. (Sessão de 14 de Junho 1839 , p. 386)

Vasconcelos critica, em vários momentos de seu longo pronunciamento, o artigo $14^{\circ}$ do projeto, que previa a necessidade de cursar estes estudos comuns para ocupar os cargos públicos. Na prática, ele, ex-ministro, se fundamentava no fato de que não haveria tantos postos de trabalho quanto o número de candidatos que se habilitariam aos mesmos. Para o senador,

e com efeito, dedique-se, como quer o nobre Senador [Feijó], toda a mocidade a estas ciências, habitue-se a mocidade a vida retirada e de meditação, por muitos que sejam os empregos do pais, nunca serão tantos quantos os candidatos que este projeto vai por em campo; nunca, dizia eu, serão tantos os empregos que cheguem para satisfazer aos diversos pretendentes. Um grande número deles terá que escolher, ou entrar em uma vida laboriosa ou braçal, ou no partido dos agitadores do pais. (Sessão de 12 de junho de 1839, p. 374)

Feijó o contrapõe na sessão seguinte:

Ninguém constará que em um governo representativo é de suma importância que os cidadãos tenham aquelas noções indispensáveis para o desempenho dos cargos públicos; diversos escritos tem reconhecido que os governos despóticos abominam a difusão das luzes, porque só serve para que os povos tenham conhecimentos de seus direitos e deveres; eles apresentam que os governos despóticos só devem proporcionar o estudo da religião católica, porque ela recomenda a obediência passiva às autoridades; porém não acontece assim nos governos representativos, por 
isso que neles os cidadãos tem muita ingerência nos negócios públicos, o que não se dá no regime absoluto. (Sessão de 14 de junho de 1839, p. 385)

O senador Vasconcelos é a favor de uma educação dual, para pobres e ricos, sem meias palavras:

O rico, o pobre estudarão as primeiras letras; o menos abastado, ainda que se não dedique ao estudo das ciências superiores, vá instruir-se nas escolas primarias superiores, onde só aprenderá o que convier aos deveres e necessidades do lugar que ocupa na sociedade; os mais abastados, que podem dedicar todo o seu tempo ao estudo das ciências freqüentarão as universidades, as escolas das ciências superiores; eis como se deve formar um plano de educação para o país. (Sessão de 12 de junho de 1839, p. 370)

É justamente esta educação dual que Feijó confronta quando intenta estabelecer uma educação comum que atingiria todo o Império e todos os cidadãos:

Disse-se também que este projeto não era adaptável a todas as classes da sociedade, mas cumpre observar que nele só se trata da instrução necessária a todos os cidadãos, que depois de adquiri-la, podem aplicar-se aos conhecimentos superiores que mais Ihes convenham e para cujo estudo não lhes serão inúteis as noções preparatórias, como, por exemplo, a higiene aos agricultores. (Sessão de 14 de junho de 1839, p. 386)

Pelo trâmite parlamentar a discussão realizada fugia um pouco da rotina, pois o debate deveria restringir-se a avaliar a utilidade ou inutilidade do projeto, como Feijó reiteradas vezes lembrou aos pares. Assim, apesar das imperfeições apontadas por alguns senadores, o projeto foi aprovado e passou a segunda discussão.

Deste episódio muitas questões ainda requerem respostas mais apuradas. Se todos os senadores, em princípio, apoiavam a necessidade de uma educação comum o que fez com que tal iniciativa fosse obliterada por tanto tempo? Quais foram os empecilhos que fizeram prevalecer a interpretação que a educação primária seria um prerrogativa exclusiva das províncias? Em que sentido uma educação mais coadunada com a perspectiva iluminista demorou tanto tempo para implantar-se no Brasil?

Com efeito, estas questões, hodiernamente, também estão relacionadas com a introjeção de currículos ocultos, representativas de tentativas de implantação de pensamento único ou, quiçá, de uma ciência única que se abrigam em estruturas curriculares mínimas nacionais abalando $o$ equilíbrio federativo e mesmo a heterogeneidade cultural da nação. Qual o justo limite para a oscilação deste pêndulo? Qual o grau de compartilhamento, imposição, autonomia envolvido nas diversas instâncias administrativas: União, Estado e Município? Qual o papel da sociedade e dos docentes e discentes neste processo?

\section{Referências}

ALMEIDA, José Ricardo Pires de. História da instrução pública no Brasil (1500-1889). Brasília: Inep, 1989.

AZEVEDO, Fernando de. A cultura brasileira. Brasília: UNB; Rio de Janeiro: UFRJ, 1996. 
BARROSO, José Liberato. A instrução pública no Brasil. Pelotas: Seiva, 2005.

BRASIL. Constituição política do império do Brasil seguida do acto addicional, da lei da sua interpretação e de outras. Rio de Janeiro: Eduardo \& Henrique Laemmert, 1863.

CARVALHO, Laerte Ramos de. As reformas pombalinas da instrução pública. São Paulo: Saraiva/USP, 1978.

CASTANHA, André Paulo. $O$ ato adicional de 1834 na história da educação brasileira. Revista Brasileira de Historia da Educação. Campinas, n. 11, 2006, p. 169-96.

COSTA, Emilia Viotti da. Da monarquia a republica: momentos decisivos. São Paulo: Unesp, 1999.

CUNHA, Luiz Antonio. A universidade temporã: o ensino superior da Colônia à Era Vargas. Rio de Janeiro: Civilização Brasileira, 1980.

CURY, Carlos Roberto Jamil. Os parâmetros curriculares nacionais e o ensino fundamental. Revista Brasileira de Educação, v. 1, n. 2, 1996, p. 4-17.

ELLIS JUNIOR, Alfredo. Diogo Antonio Feijó e a primeira metade do século XIX. São Paulo: Brasiliana, 1980.

FLEURY, Renato Sêneca de. Padre Feijó. São Paulo: Melhoramentos, 1958.

GONDRA, José Gonçalves; SCHUELER, Alessandra. Educação, poder e educação escolar na corte imperial. Rio de Janeiro: Uerj, 2008.

GONDRA, José Gonçalves (org.). Educação e instrução nas províncias e na Corte Imperial (Brasil, 1822-1889). Vitória: Edufes, 2011.

HAIDAR, Maria de Lourdes Mariotto. O ensino secundário no império brasileiro. São Paulo: Grijalbo/USP, 1972.

HOLANDA, Sergio Buarque de. História geral da civilização: o Brasil monárquico. São Paulo: Difel, 1985.

MARTINS, Wilson. História da inteligência brasileira. São Paulo: Cultrix/USP, 1977.

MATTOS, Luiz Alves de. Primórdios da educação no Brasil. Rio de Janeiro: Aurora, 1958.

MOACYR, Primitivo. A instrução e o império. (1823-1853). São Paulo: Nacional, 1936.

$\mathrm{RICCl}$, Magda Maria de Oliveira. Assombrações de um padre regente: Diogo Antonio Feijó (1784-1843). Campinas: Unicamp, 2001.

ORICO, Osvaldo. Feijó: o demônio da regência. Rio de Janeiro: Civilização Brasileira, 1932.

SAVIANI, Dermeval. Historia da idéias pedagógicas no Brasil. Campinas: Autores Associados, 2007.

SESSÃO do Congresso Nacional. In: Annaes do Senado do Império do Brasil de 4 de maio a 17 de junho de 1839. Rio de Janeiro: Congresso Nacional, 1912.

SOUSA, Otávio Tarquinio de. Diogo Antonio Feijó (1784-1843). Rio de Janeiro: José Olympio, 1942.

SUCUPIRA, Newton. O ato adicional de 1834 e a descentralização da educação. In: Fávero, Osmar (org.). Educação nas constituintes brasileiras 1823-1988. Campinas: Editores Associados, 1996. 
EDUARDO ARRIADA é professor na Universidade Federal de Pelotas, integrante do Centro de Estudos e Investigações em História da Educação. Associado à Associação de Pesquisadores em História da Educação e à Sociedade Brasileira de História da Educação. Coordenador do Centro de Documentação - Pelotas/RS.

Endereço: Rua D. Pedro II, 414 - 96010-300 - Pelotas, RS - Brasil.

E-mail: earriada@hotmail.com.

ELOMAR ANTONIO CALLEGARO TAMBARA é professor de História da Educação na Universidade Federal de Pelotas, integrante do Centro de Estudos e Investigações em História da Educação e associado à Associação Sul-Rio-Grandense de Pesquisadores em História da Educação.

Endereço: Caixa postal 628 - 96010-700 - Pelotas - RS - Brasil.

E-mail: tambara@ufpel.edu.br.

Recebido em 10 de março de 2014.

Aceito em 23 de julho de 2014. 


\section{PROJETO}

\section{A Assembléia Geral Legislativa decreta:}

Artigo $1^{\circ}$ - Haverá em todo o Império cursos de estudos elementares em círculos para esse fim destinados.

Artigo $2^{\circ}$ - Nestes cursos ensinar-se-ão elementos de História Natural, Física e Química em uma só cadeira; elementos de Geografia, Metafísica e Lógica em outra cadeira; Filosofia moral, contendo a teoria desta ciência, o Direito Natural e Político noutra cadeira.

Artigo $3^{\circ}$ - Haverá um substituto para estas três cadeiras.

Artigo $4^{\circ}$ - Na capital de cada província haverá três cadeiras, uma de Latim e Francês, outra de Aritmética e Geografia; outra de Retórica e Poética.

Artigo $5^{\circ}$ - Os presidentes marcarão os círculos, tendo em vista a comodidade dos estudantes, contanto, porém, que cada círculo compreenda trinta a cinqüenta mil habitantes livres.

Artigo $6^{\circ}$ - O Governo determinará provisoriamente aos mestres ordenados proporcionados aos diferentes círculos. Ordenará estatutos, e mandará formar compêndios, tendo em vista o plano junto.

Artigo $7^{\circ}$ - O Governo, na seguinte Legislatura, participará à Assembléia de tudo isto, de que fica encarregado, com as observações que julgar convenientes, para ser definitivamente deliberado.

Artigo $8^{\circ}$ - Todas as cadeiras de latim, ora existentes fora das capitais, ficam abolidas por morte dos professores ou pela passagem destes a algumas das novas cadeiras.

Artigo $9^{\circ}$ - O Governo, pela primeira vez, nomeará professores naturais, os estrangeiros para as cadeiras criadas pela presente lei, e nas vagas serão elas providas por concurso na forma até aqui praticada.

Artigo $10^{\circ}$ - Nas capitais mais populosas poderá o Governo, se julgar necessário, criar cadeiras separadas para cada uma das artes e ciências aqui declaradas, onde devidamente se habilitem os candidatos para as cadeiras criadas pela presente lei, e arbitrar-Ihes suficiente ordenado.

Artigo $11^{\circ}$ - Os professores serão jubilados depois de vinte e cinco anos de bom serviço com o ordenado por inteiro e se tiverem bons serviços e se inabilitarem de 
continuar a presta-los para completar os vinte e cinco anos, serão jubilados com o ordenado correspondente aos anos de serviço que prestaram.

Artigo $12^{\circ}$ - Nenhum cidadão menor de 14 anos, que residir no lugar em que estiverem providas as cadeiras aqui declaradas, poderá para o futuro pretender emprego algum, quer de eleição popular ou de nomeação de qualquer autoridade, sem apresentar primeiro à autoridade a quem competir conhecer o seu diploma ou dar-lhe posse, certidão de idade e atestado dos professores de haver freqüentado o curso completo, embora sem notável proveito.

O Governo, nos estatutos que der, marcará o menor prazo possível, em que se finalizem os estudos das matérias que se devem ensinar em cada uma das cadeiras com proveito.

Paço do Senado, 17 de maio de 1839. 